\title{
ESPAÇOS MENTAIS NA CONCEPTUALIZAÇÃO DE CONVERSA: DOIS MODELOS EM ANÁLISE*
}

\section{MENTAL SPACES IN CONVERSATION CONSTRUAL: TWO MODELS IN ANALYSIS}

\author{
Sandra Bernardo \\ Naira Velozo ${ }^{2}$ \\ Juan de $\mathrm{Abreu}^{3}$
}

\begin{abstract}
RESUMO
Apresenta-se, neste artigo, análise de excertos de uma conversa à luz da Teoria dos Espaços Mentais (TEM), proposta por Fauconnier (1997), e da Rede de Espaços Comunicativos Básicos (RECB) de Ferrari e Sweetser (2012), com objetivo de evidenciar a adequação da RECB para descrição da organização conceptual de conversa. Os trechos analisados foram extraídos da amostra de Bernardo (2002), que consiste na transcrição de uma conversa, com cerca de 30 minutos, gravada durante um jantar, em 1988, com a participação de cinco pessoas. Por meio do confronto entre os modelos da TEM e da RECB para análise da interação verbal, foi possível alcançar mais refinamento teórico e metodológico, já que a postulação de uma base (ground) composta de outros espaços ativados ao longo da construção de sentido da interação em andamento permitiu abarcar conceitos que foram aliados à análise com base na TEM. A retomada da análise de Bernardo (2002) com base na RECB revelou, portanto, um aprimoramento na descrição da organização conceptual de conversa em termos de seus aspectos linguísticos, contextuais e interacionais.
\end{abstract}

PALAVRAS-CHAVE: Conversa; Rede de Espaços Comunicativos Básicos; Linguística Cognitiva.

\begin{abstract}
This article presents an analysis of excerpts from a conversation in the light of the Mental Spaces Theory (MET), proposed by Fauconnier (1997), and the Basic Communicative Spaces Network (BCSN) by Ferrari and Sweetser (2012), to demonstrate the adequacy of BCSN to describe the conceptual organization of conversation. The analyzed excerpts were extracted from Bernardo's sample (2002), which consists of the transcription of a conversation, with about 30 minutes, recorded during a dinner, in 1988, with the participation of five people. Through the confrontation between the MET and BCSN models for the analysis of verbal interaction, it was possible to achieve more theoretical and methodological refinement, since the postulation of a ground composed of other spaces activated along the construction of meaning of the interaction in progress has allowed encompassing concepts that were allied to the analysis based on MET. The resumption of Bernardo's analysis (2002) based on the BCSN revealed, therefore, an improvement in the description of the conceptual organization of conversation in terms of its linguistic, contextual and interactional aspects.
\end{abstract}

KEYWORDS: Conversation; The Basic Communicative Spaces Network; Cognitive Linguistics.

\footnotetext{
*Produção ligada ao projeto FAPERJ no E-26/010.000145/2016.

1 Professora Associada da Universidade do Estado do Rio de Janeiro. Doutora em Linguística pela UFRJ. E-mail: sandrabernardo61@gmail.com.

2 Professora Adjunta da Universidade do Estado do Rio de Janeiro. Doutora em Letras Vernáculas pela UFRJ. E-mail: naira_velozo@yahoo.com.br.

${ }^{3}$ Professor na Yelding English School Ltda.; IC-UERJ (2016-2018). Graduado em Letras (Português-Espanhol) pela Universidade do Estado do Rio de Janeiro. E-mail: juancosmeabreu@hotmail.com.
} 


\section{INTRODUÇÃO}

Neste artigo, analisamos trechos de transcrições de língua falada à luz da Teoria dos Espaços Mentais (TEM), proposta por Fauconnier (1994, 1997), e da Rede de Espaços Comunicativos Básicos (RECB) de Ferrari e Sweetser (2012). Para tal, será retomado parte do trabalho de Bernardo (2002), em que foram analisados trechos de uma conversa, com cerca de 30 minutos, gravada durante um jantar, em 1988, com a participação de cinco pessoas. Nessa interação, os falantes abordam vários tópicos.

A proposta de trabalhar com modelo de RECB (SANDERS; SANDERS; SWEETSER, 2009, FERRARI; SWEETSER, 2012; FERRARI; PINHEIRO, 2014) na conceptualização de conversas foi pautada na hipótese de que esse modelo representaria avanço em termos teóricos e metodológicos, em razão da postulação de uma base (ground) composta de outros espaços ativados ao longo da construção de sentido da interação em andamento. Bernardo (2002) trabalhou com a TEM, ao postular uma organização conceptual da conversa com base no encadeamento tópicodiscursivo e referencial, a partir dos espaços FOCO e PONTO DE VISTA, responsáveis pela ativação de conteúdos defendidos pelos participantes ao longo da interação.

Para alcançar tal objetivo, outras ferramentas teóricas foram recrutadas, na medida em que a TEM foi criada para trabalhar com a ativação e o encadeamento dos referentes recrutados ao longo da construção de sentido da conversa. Entre as ferramentas teóricas e metodológicas, Bernardo (2002) aliou a TEM a (i) conceitos de Clark (1996); (ii) estudos de análise de conversa, no tange à configuração de turnos conversacionais; (iii) classificação semântico-discursiva do conteúdo abordado pelos falantes (Bernardo, 1995), visto que conceitos ligados à análise de conversa (turno, par adjacente etc.) foram considerados adequados à descrição da estrutura conversacional, mas não do conteúdo expresso. Contudo, acredita-se que algumas ferramentas teóricas utilizadas em Bernardo (2002) podem ser contempladas pela RECB, de modo a alcançar uma melhor descrição da conceptualização de interações verbais, englobando as intenções e os tipos de argumentos utilizados pelos falantes.

A fim de demonstrar a adequação teórica da RECB, na próxima seção, será apresentado um excerto da análise para conceptualização da conversa proposta em Bernardo (2002) com base na TEM. Em seguida, essa análise será confrontada com uma análise a partir da RECB. Tais seções configuram etapas textuais teórica e analítica simultaneamente. Por último, serão tecidas as considerações finais, seguidas pelas referências bibliográficas.

\section{Espaços mentais na conceptualização de conversa}

Os excertos selecionados ${ }^{4}$ para análise integram os resultados de uma pesquisa qualitativa de base indutiva, cujo objetivo foi gerar reflexões acerca do escopo descritivo do modelo de Rede de Espaços Comunicativos Básicos (RECB). Quanto aos procedimentos técnicos empregados em sua realização, a pesquisa pode ser caracterizada predominantemente bibliográfica, devido ao papel dos conceitos na análise dos dados e ao fato de as amostras fala já estarem registradas documentalmente.

Iniciamos esta seção com o excerto (1), por se tratar do trecho inicial da gravação, analisado em Bernardo (2002), cuja representação postulada para a conceptualização do fragmento discursivo é ilustrada na Figura 1 com a configuração de espaços conceptuais de dois trechos desse excerto. O conteúdo expresso pela falante $\mathrm{C}^{5}$ consiste em uma história sobre um membro da família considerado comilão. A narrativa funciona como uma evidência para defesa dessa característica.

\footnotetext{
4 Ao longo da pesquisa (2016-2018), também foram analisadas as interações do Banco de dados interacionais (Roncarati, 1996). Porém, neste texto, para destacar a análise com base nos dois modelos, selecionamos apenas trechos de Bernardo 2002.

${ }^{5}$ Os falantes são referenciados pelas iniciais de seus nomes.
} 


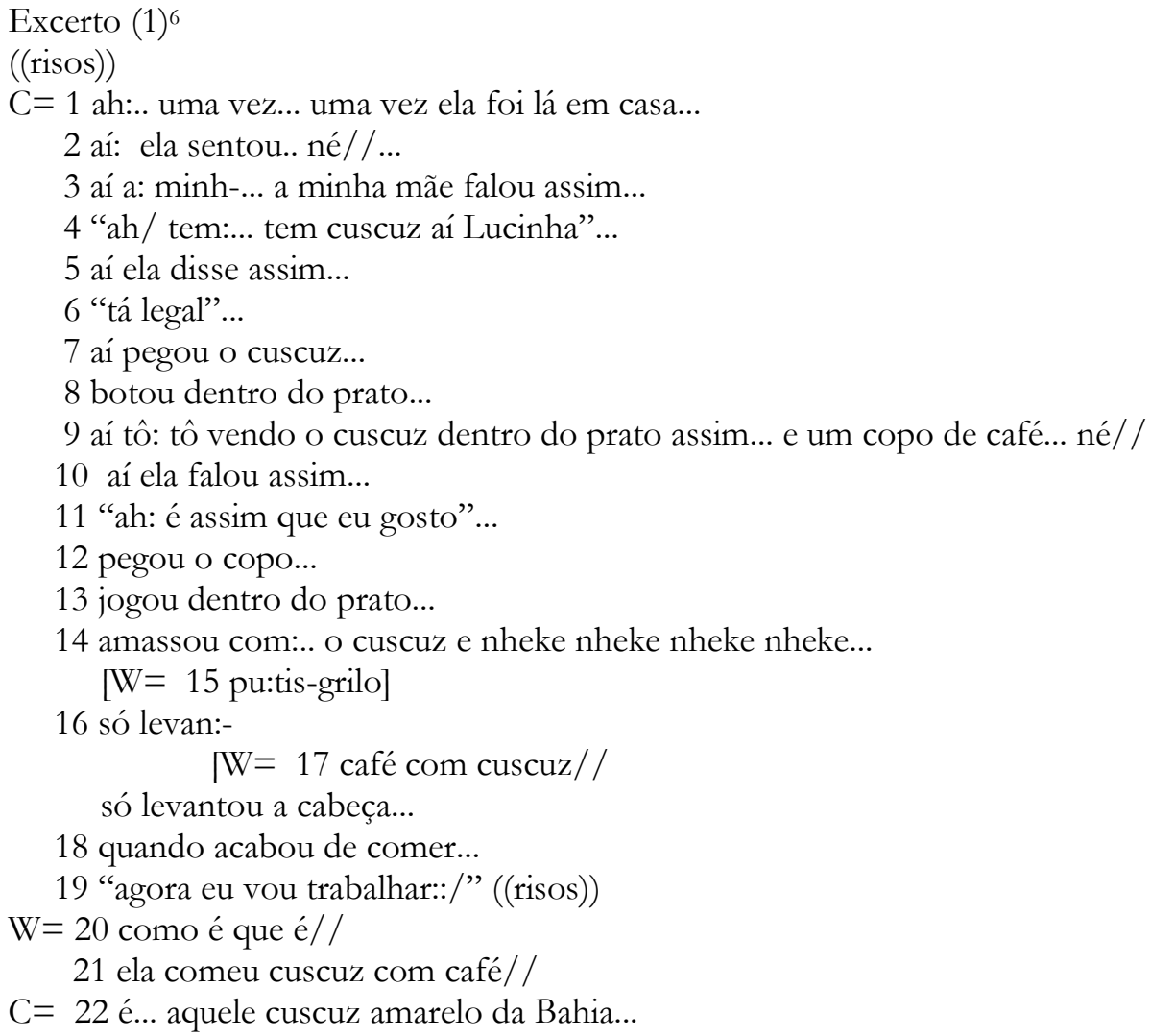

A configuração de Bernardo (2002) expressa o papel da TEM no encadeamento referencial do conteúdo expresso pelos falantes. Para dar conta de como os espaços FOCO e PONTO DE VISTA seriam responsáveis pela organização da conversa, vista como uma construção conjunta (CLARK, 1996), Bernardo (2002) precisou aliar outros conceitos, entre eles a noção de domínio, a fim de descrever as alternâncias entre o aqui e agora da conversa e o deslocamento de foco de atenção (FOCO) para a ativação de narrativas. Assim, na representação da Figura 1, o sinal @ representa o papel de experienciador, consequentemente o de narrador da falante $C$, que vivenciou os fatos relatados.

Logo, com a TEM, foi possível avançar na descrição da organização conceptual da conversa em termos de como os enunciados expressos seriam mantidos em atenção, recuperados e introduzidos ao longo da interação por meio do princípio de acesso (FAUCONNIER, 1997) e princípios de organização de discursiva para gerenciamento do processamento de tempo verbal gramatical em relação ao momento da fala, novamente outro aspecto ligado ao encadeamento referencial ativado ao longo da interação. Esse caráter da TEM se mostrou relevante para a organização da conversa, porque as formas linguísticas funcionam como gatilhos para ativação de referentes que ativam conteúdos expressos, debatidos pelos falantes.

\footnotetext{
${ }^{6}$ Foram usados na transcrição os seguintes símbolos: /.../ - transcrição parcial; [[ - falas simultâneas; [ - sobreposição de vozes; ... ou (+) - pausas; ( ) - falta de clareza na audição; - trechos descartados, palavras inconclusas e truncamentos bruscos; LETRA MAIÚSCULA - ênfase ou acento forte; :: - alongamento de vogal ou consoante; (( )) - comentários do analista; // - entonação interrogativa; / - entonação semiexclamativa; \ - entonação descendente. Os turnos foram segmentados com base no conceito de unidade de ideia/ entonação de Chafe $(1987,1988)$.
} 
Figura 1 - Configuração de espaços mentais - TEM

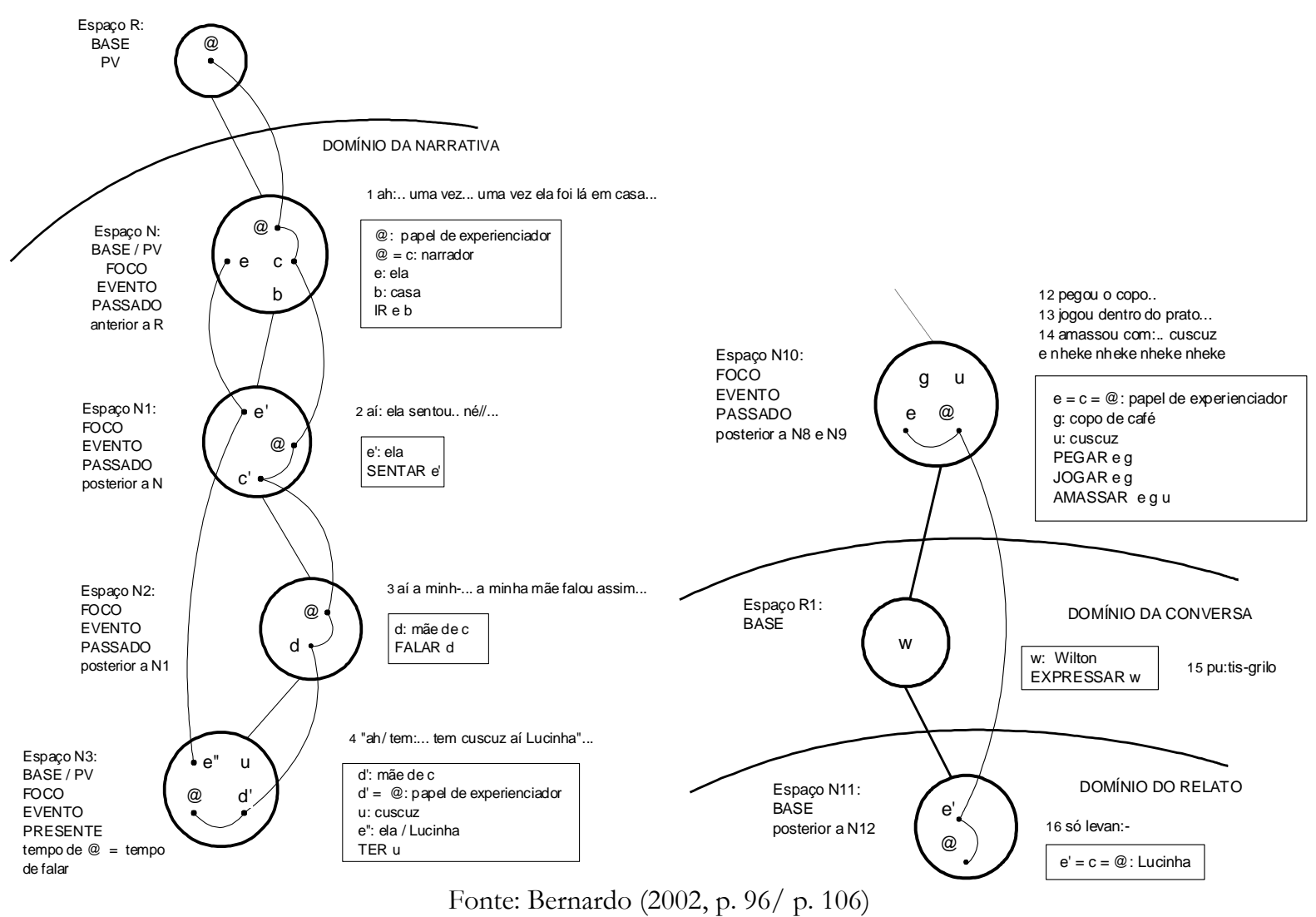

Não obstante o potencial analítico da TEM, por meio das funções pragmáticas e do princípio de acesso, de modo a possibilitar a ligação entre os espaços mentais abertos com elementos ativados de forma otimizada para conceptualização, alguns aspectos da análise foram tomados como basilares, devido ao objeto de análise: uma conversa. Para atender ao caráter essencialmente argumentativo da conversa, além da segmentação em macroepisódios, episódios e eventos com base nos tópicos e subtópicos abordados pelos falantes, foi pontuada, ao longo da análise, uma categorização do papel semântico-pragmático dos enunciados verbalizados pelos participantes da interação, conforme se tratasse de um comentário retórico, opinativo, refutatório, demonstrativo, metadiscursivo, humorístico e de assentimento. O termo "comentário" foi empregado como contraponto às sequências narrativas da interação (Bernardo, 1995).

Essa categorização de Bernardo (1995), que será retomada na próxima seção, perpassou as explicações da construção de sentido conjunta da conversa em Bernardo (2002), porém não foi relacionada explicitamente aos espaços mentais abertos para organização conceptual (construal) da interação. Assim como a segmentação em (macro)episódios/eventos, tal categorização serviu de expediente teórico e metodológico de análise da conversa como um produto, semelhante à segmentação dos turnos em termos formais, enquanto a descrição dos espaços mentais permitiu a análise da construção da conversa em termos processuais, dinâmicos.

Outro fundamento empregado em Bernardo (2002) foi a noção de base comum de Clark (1996). A fim de explicar como os projetos mínimos podem ser desenvolvidos com sucesso, visando a um projeto conjunto, Clark (1996, p. 221) apresenta a hipótese de que as pessoas devem buscar um terreno comum para o que executarão em conjunto, ou seja, estabelecer esse terreno comum como parte da base comum suficiente para o propósito do momento. Tal base comum (grounding) deve ocorrer em todos os níveis da comunicação. 
De acordo com essa hipótese, "o discurso consiste em duas pistas paralelas de ação" (CLARK, 1996, p. 241): a primeira sobre a interação/negociação em curso; a segunda sobre o ato comunicativo. "Os indivíduos desejam e são capazes de agir independentemente, todavia as ações conjuntas requerem comprometimento de todos os participantes" (CLARK, 1996, p. 289). Logo, para que um projeto conjunto se realize, é necessário um engajamento de todos os envolvidos na atividade conjunta, estabelecendo um objeto social.

Ao longo da produção de um discurso, os falantes vão deixando pistas de uma representação discursiva, composta de duas partes essenciais: (i) uma representação textual, a representação da linguagem e outros sinais usados durante o discurso; e (ii) uma representação situacional, representação da situação sobre a qual se fala. Na Figura 2, ilustramos o modelo de representação discursiva postulado por Clark (1996, p. 52-54).

Figura 2 - Modelo de representação do discurso

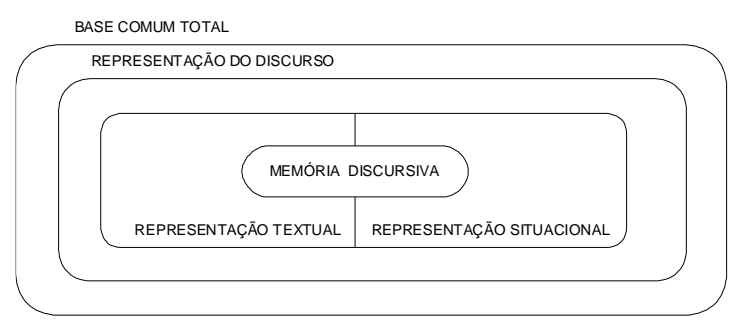

Fonte: Clark (1996, p. 52-54)

Para que as pessoas se entendam completamente, devem ter representados, como parte de sua base comum, pelo menos alguns aspectos dos seguintes sinais: (i) sons produzidos; (ii) expressões emitidas; (iii) palavras, sintagmas, orações e sua configuração sintática; (iv) significado das palavras, dos sintagmas e das orações expressas; e (v) turnos constituindo uma troca. Esses são alguns aspectos da representação textual, alguns dos sinais necessários à compreensão do que é dito entre dois participantes, por exemplo.

Além disso, é preciso deixar pistas da situação sobre a qual está tratando na representação situacional, que inclui os seguintes elementos: (i) participantes, tempo, lugar e todo contexto/ambiente pertinente; (ii) referentes de todas as expressões usadas (eu, você, aqui, cantaremos); (iii) comprometimento social estabelecido por aquilo que os falantes estão dizendo (promessa e aceitação, por exemplo); e (iv) fatia mais ampla realizada pela troca. Parte da representação situacional toma forma em uma representação externa, como uma cena em que um cliente vai a uma drogaria comprar um remédio.

Logo, a representação situacional consiste no que os participantes estão realizando, e a representação textual, nas estratégias comunicativas para desempenhar essas ações. A memória ou registro do discurso (discourse record) desfruta de um status privilegiado, pois representa os estágios e eventos oficiais da atividade conjunta em curso. A memória discursiva de um jogo de xadrez, por exemplo, conteria todos os lances da partida.

Conversações são intencionais (purposive), porém não planejadas. Os indivíduos alcançam, na maioria das vezes, o que pretendem significar nos projetos conjuntos, sejam amplos ou menores, com os quais estão comprometidos, quando estabelecem propósitos conjuntos. Com intuito de completar tais intentos, é preciso trabalhar em nível de projetos mínimos através dos quais negociam propósitos mais amplos. Conversas só parecem planejadas e objetivamente orientadas retrospectivamente; na verdade, são criadas oportunisticamente, pedaço por pedaço, à medida que os participantes negociam propósitos conjuntos e tentam atingi-los (CLARK, p. 319).

Com base nessa visão, a estrutura hierárquica da conversação é uma propriedade emergente, que surge em razão dos princípios que governam qualquer atividade conjunta bem-sucedida. A conversação não acontece sem uma coordenação de conteúdo e processo; por 
isso, os participantes tentam completar cada ação conjunta. Portanto, a organização da conversa emerge de ações conjuntas planejadas localmente e produzidas oportunisticamente. Durante as interações, os falantes emitem pistas das etapas das ações em curso, sinalizando, indicando ou demonstrando seus propósitos. Trabalham em conjunto para completar os níveis de execução e atenção, apresentação e identificação, sinalização e construção, propósito e realização. Uma vez que tais princípios são aplicados, pares adjacentes, partes de conversas ou conversas inteiras simplesmente surgem (CLARK, p. 320).

Essa base comum foi incorporada à análise de Bernardo (2002) por meio da representação de um espaço-base para cenário conversacional, ou seja, a realidade da conversa. Assim, postulou-se a subjacência de uma base comum $\left(\mathrm{R}_{0}\right)$, que compreende todo conhecimento de mundo dos falantes, suas crenças, opiniões, inferências, bem como seus diários pessoais. Nesse espaço-base, estão representadas as contrapartes de I, W e C (participantes ativos da interação), ligadas pelo princípio de acesso aos espaços a serem criados no decorrer da conceptualização do discurso, conforme a Figura 3.

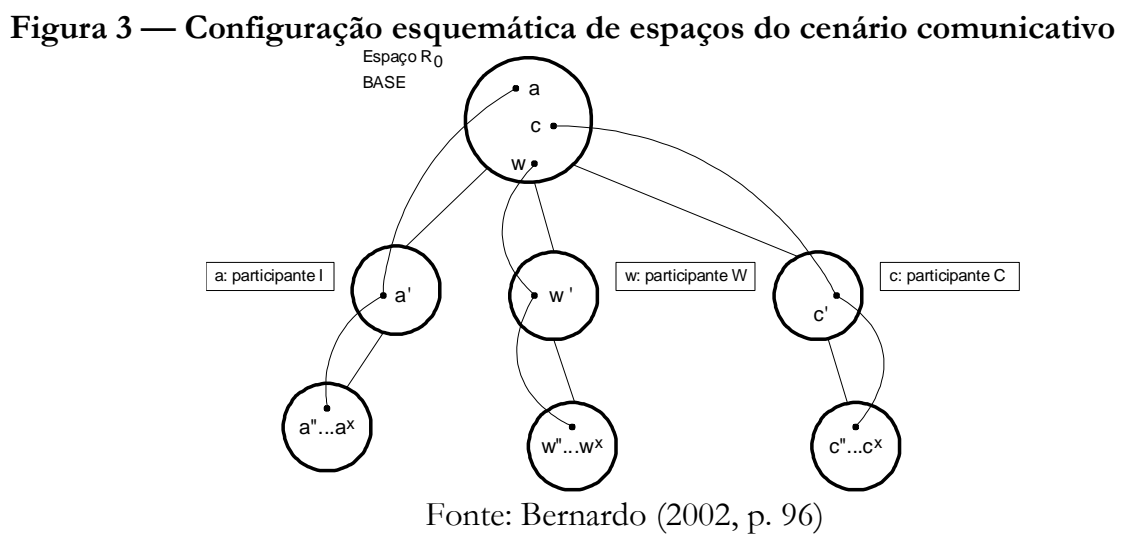

O espaço base da realidade da conversa, $\mathrm{R}_{0}$, representaria a base comum a partir da qual os espaços para a construção de sentidos serão ativados pelos falantes. Essa representação buscou demonstrar o papel de cada participante na construção conjunta. Todavia, o modelo de RECB propicia essa base comum, assim como abarca a categorização dos comentários semânticopragmáticos adotados em Bernardo $(1995,2002)$, o que permitiu refinar o modelo de Bernardo (2002).

\section{Da Teoria dos Espaços Mentais à Rede de Espaços Comunicativos Básicos}

O modelo de Rede de Espaços Comunicativos Básicos (RECB) de Sanders, Sanders e Sweetser (2009), que retoma Dancygier e Sweetser (2005), consiste em uma especificação, em termos de espaços mentais, das estruturas básicas mínimas envolvidas em uma base para interação: não apenas um falante e um ouvinte que interagem em um contexto imediato, mas alguns espaços básicos assumidos pelo falante como realidade, além do conteúdo dos estados epistêmicos do falante e do conteúdo da comunicação explicitamente expresso. Em essência, comunicar-se envolve, por parte dos usuários de língua, estados mentais que expressam determinada configuração de ato de fala, utilizando determinado conjunto de formas linguísticas.

Ferrari e Pinheiro (2014), a partir de Ferrari e Sweetser (2012), propõem uma RECB composta pelos seguintes espaços mentais: (i) espaço base (Ground), ou espaço da realidade: cenário espaço-temporal real de falante e ouvinte; (ii) espaço epistêmico: conhecimento das crenças e processos de raciocínio de falante e ouvinte, que estão também no background da comunicação; (iii) espaço de ato de fala das interações realizadas (declaração, pergunta); (iv) espaço metalinguístico das formas linguísticas partilhadas, que pode ser referenciado se as escolhas de uso 
são colocadas em consideração ou disputadas; espaço metatextual, que contém os registros do discurso compartilhado. Na Figura 4, ilustramos a representação dessa configuração de RECB, com base na arquitetura de Ferrari e Sweetser (2012).

Figura 4 - Rede de Espaços Comunicativos Básicos

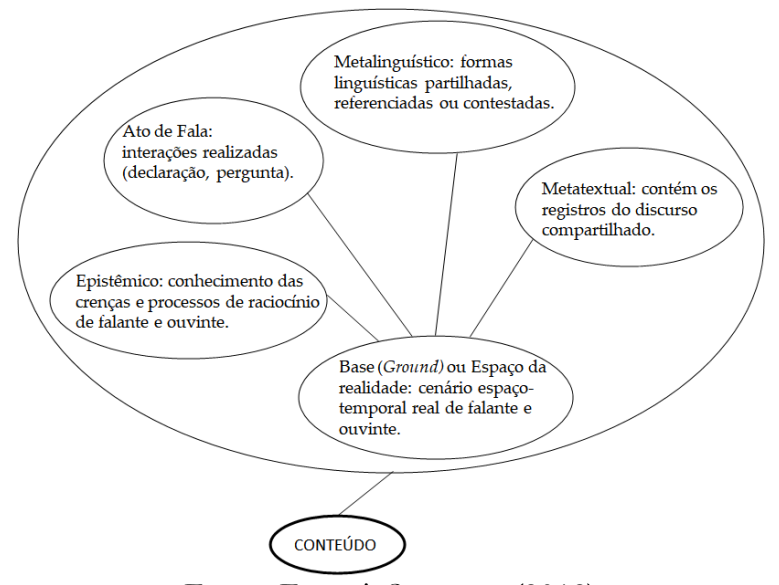

Fonte: Ferrari; Sweetser (2012)

A possibilidade de avançar na descrição conceptual de conversa foi o fator motivador para submissão dos dados de Bernardo (2002) ao modelo de RECB, visto que, no ground, poderiam ser processados os comentários, postulados em Bernardo (1995, retomados em 2002), acerca do papel semântico-pragmático de argumentos, declarações e perguntas, entre outros enunciados expressos pelos falantes. Assim, na Figura 5, ainda de forma bem simplificada, é possível verificar o potencial desse modelo com uma base comum (ground) ativada e partilhada pelos falantes ao longo de uma interação.

Figura 5 - Configuração de espaços mentais - REBC

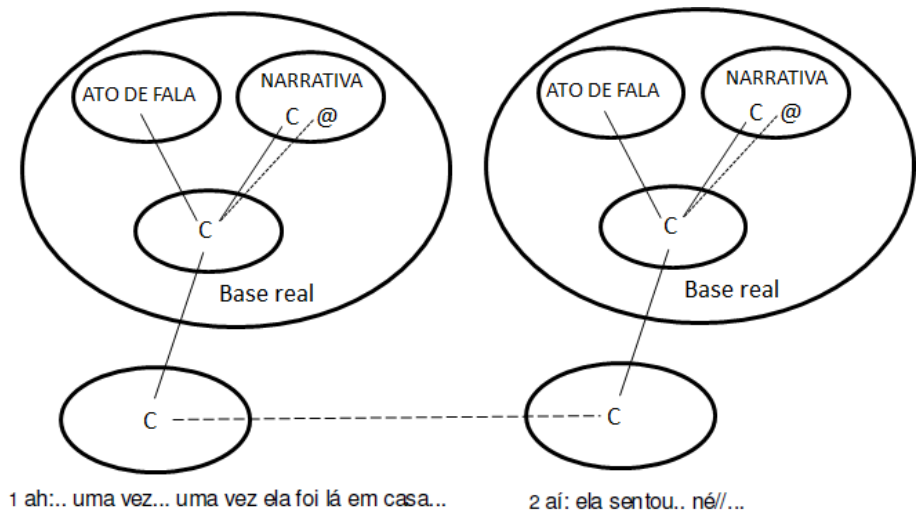

Fonte: Autores

Como pode ser observado, na Figura 5, referente às primeiras unidades de ideia (ou entonacional) do excerto (1), os enunciados de $\mathrm{C}$ podem ser representados tanto em termos referenciais, abarcando aspectos teóricos cobertos pela TEM, quanto em termos de conteúdo enunciado e de seu papel na construção de sentido conjunta da interação. Como a fala de $\mathrm{C}$, no excerto (1), funciona como uma evidência do apetite exagerado de Lucinha, pode ser considerado um espaço de ato de fala na RECB. Além disso, o trecho de narrativa pode ser considerado um espaço metatextual, na medida em que os todos participantes, incluindo a narradora, acompanham o andamento do discurso, compartilhando-o. 
Em termos ortodoxos, com base nas aplicações desse modelo à conceptualização de formas linguísticas e na TEM, da qual tal modelo se originou, acreditamos que cada unidade de ideia do excerto (1) configuraria uma representação como a da Figura 5. Contudo, a representação da Figura 5 precisava ainda incluir outros aspectos envolvidos na interação, por um lado, e ser otimizada, por outro, visto que não seria econômico postular um esquema para cada unidade de ideia. Assim, com vistas a atender a esses aspectos, várias representações foram experimentadas, entre elas, a representação iniciada para todo o excerto (1) na Figura 6.

Observa-se, na Figura 6, uma tentativa de configuração para a inclusão de mais aspectos ativados no excerto (1), por meio da representação dos seguintes espaços: (i) Base real, espaço da realidade em que ocorre a integração, ou seja, o aqui e agora da conversa; (ii) ATO DE FALA, espaço aberto para as interações entre os falantes, composto de subespaços que configuram as declarações de $\mathrm{C}$ em forma de narrativa e as interrogações e declarações de $\mathrm{W}$ (unidades 20 e 21), em razão do espanto e do não acesso ao tipo de cuscuz a que se refere $\mathrm{C}$, visto que, como carioca, não conhece o cuscuz amarelo típico da culinária nordestina; (iii) METATEXTUAL, espaço que compreende o relato de C. Esses espaços compõem a BASE COMUM (GROUND). A conexão entre os espaços de conteúdo em FOCO e os espaços mais altos - ATO DE FALA e METATEXTUAL - é mediada pelo espaço da Realidade (Base real).

\section{Figura 6 - Configuração de espaços mentais na RECB}

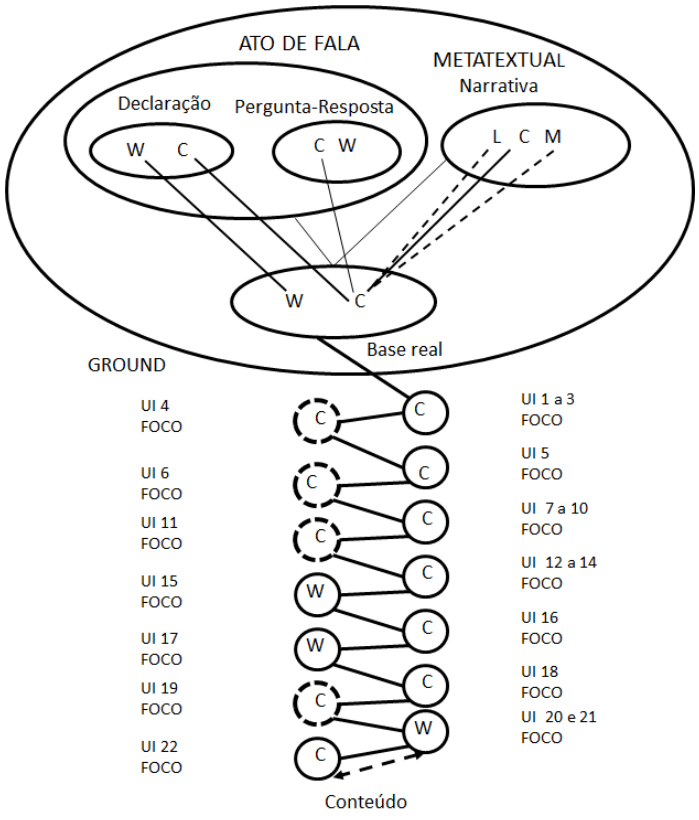

Fonte: Autores

Embora essa conexão ocorra em nível conceptual online, os espaços mais altos requerem inferências, percepção de intenções, lembranças, enfim, estratégias de raciocínio variadas a serem recrutadas durante a conceptualização. As linhas pontilhadas são usadas para ligar a representação de $C$ na Base real e os personagens $L$ e $M$, cujas falas são reportadas por $C$, porque $L$ e $M$ não participam fisicamente da interação. Como é costume na Linguística Cognitiva, as letras em versalete/maiúsculas, referenciam o que se encontra em nível conceptual. Apenas as iniciais maiúsculas representam um conteúdo expresso ou sinalizado linguisticamente, por isso Narrativa, Declaração, Pergunta-Resposta e Base real estão grafados dessa forma.

Os espaços de conteúdo são compostos pela representação dos participantes que enunciam as unidades de ideia. Tais conteúdos vão sendo colocados em FOCO durante a interação. $\mathrm{Na}$ configuração da Figura 5, novos espaços são abertos, quando há troca de turno entre os 
participantes e/ou inserção de novo self no discurso, como no caso dos discursos diretos em que $\mathrm{C}$ reproduz as falas de $\mathrm{M}$ e L, alterando a voz e a entonação. Ao emprestar sua a voz a M e L, a narradora desloca o FOCO e o PONTO DE VISTA. As unidades em que tais mudanças ocorrem foram representadas por espaços pontilhados. A linha pontilhada com seta nas duas pontas assinala o par pergunta e resposta entre dois participantes.

A configuração da Figura 6 pareceu adequada ao tipo de encadeamento de unidades do excerto (1), em que há poucas alternâncias de turno e há uma oposição entre relato e enunciados expressos na Base real, ou seja, no momento da conversa. Além disso, foi possível perceber a relação entre o expediente adotado por Bernardo (2002), baseado em Clark (1996), e a noção de GROUND proposta por Ferrari e Sweetser (2012), visto que o espaço BASE da realidade da conversa, $\mathrm{R}_{0}$, ilustrado na Figura 3, representaria a base comum a partir da qual os espaços para a construção de sentidos serão abertos pelos falantes.

Com essa representação, foi possível demonstrar o papel de cada participante na construção conjunta, avançando teórica e metodologicamente na descrição da conceptualização de conversa por meio da relação entre a base comum de Clark ao ground da RECB. A representação textual de Clark é satisfeita pelo espaço METATEXTUAL, ao passo que a representação situacional é satisfeita pelo espaço Base real. O espaço de ATO DE FALA satisfaz aspectos interacionais da memória discursiva.

Além desses pontos de contato, o modelo de RECB propicia uma descrição mais detalhada, na medida em que outros espaços, como EPISTÊMICO, METALINGUÍsTICO, são incorporados ao GROUND, denominado BASE COMUM. Logo, como a RECB incorpora as representações de Clark por meio da abertura de espaços, pode ser considerado um modelo mais processual, capaz de abarcar aspectos interacionais, semânticos e pragmáticos como uma rotina cognitiva dinamicamente ativada e processada localmente durante a conceptualização conjunta da interação.

Dois aspectos, em termos de ganho teórico com adoção da RECB para conceptualização de conversa podem ser ainda apontados: (i) uma possível relação entre comentários postulados em Bernardo (1995) e espaços preconizados pelo modelo de Ferrari e Sweetser (2012); (ii) um refinamento da representação, a fim de abarcar excertos de conversas com mais alternâncias de turnos entre diferentes participantes.

A fim de ilustrar a compreensão de que os comentários usados como argumentos de análise poderiam ser integrados à BASE COMUM (GROUND), tornando-lhes mais integrados à configuração de espaços mentais ativados para a conceptualização postulada, elencamos a classificação de proposta em Bernardo (1995), seguidos de definição e exemplo, para, em seguida, tecer a relação proposta.

a) Comentários retóricos - enunciados com entonação interrogativa que não formam pares adjacentes, porque não há seleção do próximo falante e da determinação da ação deste. Além disso, o lugar relevante para transição é facultativo. Tais enunciados não seguem determinados padrões presentes nos pares adjacentes, como pode ser observado nos excertos (2) e (3), com trechos destacados em itálico.

Excerto (2)

$C=400$ eu não poderia classificar uma língua dessa como rica também/ /

401 por ter... uma: uma maneira...

$[\mathrm{I}=402$ isso eu não questiono não...

$\mathrm{C}=$ muito vasta de se expressar//

$\mathrm{I}=403$ quem questionou isso foi o Wilton...

404 eu não questionei isso não...

Excerto (3)

$\mathrm{I}=484$ quer dizer... fica muito claro que há uma luta de classe entre o operário-

485 é o...o...o...o bancário que ganha pouco e os marajás que ganham muito/ 
486 "há uma luta de classe nisso"/

487 eles nunca falam isso...

488 por que eles não fala/ /

489 você estuda Letras...

490 por que você não faz um trabalho a respeito disso/

491 essas palavras são ta- é...é tabus dentro da própria linguagem... né//

492 se...se...se eu faço Letras eu ia fazer um: uma monografia a respeito disso...

493 por que que não usar a linguagem como transformação social//

494 por que que não é usado// por que que existe o tabu//

No excerto (2), embora haja uma complementação, esta não configura uma resposta direta ao comentário, mas uma espécie de estímulo, de desafio para que o falante continue sua explanação. No excerto (3), em que não há complementação, a função retórica desse tipo de comentário tornase mais evidente, ou seja, o falante usa tais enunciados como estratégia discursiva, promovendo um efeito dramático à sua fala e arrematando o que foi dito sobre determinado tópico ou subtópico?

O papel desempenhado pelos comentários retóricos na conceptualização pode ser descrito pela relação/conexão entre os seguintes espaços mentais da RECB: ATO DE FALA, EPISTÊMICO e METATEXTUAL, porque o falante usa tais enunciados para defender uma posição, com a intenção de colocar em discussão sua crença sobre o que está sendo abordado. Para tal, tanto o falante que está de posse do turno quanto os demais participantes mantêm o registro do discurso compartilhado.

b) Comentários opinativos - enunciados em que o falante emite um juízo de valor sobre determinada questão, com entonação assertiva ou não, conforme ilustrado nos excertos (4) e (5). A conceptualização desse tipo de comentário também seria ativada pela conexão entre os espaços ATO DE FALA, EPISTÊMICO e METATEXTUAL, em razão do papel desempenhado na construção conjunta da conversa.

Excerto (4)

$\mathrm{W}=226$ com uma familia dessa eu vou te contar heim...

227 tem que ser mui:to... / ... / muito equilibrada...

229 senão fica igual... né//

Excerto (5)

I= 430 então é o seguinte... u::: é:: você... você observa o seguinte...

431 que determinadas- é...é tipos de: comunicação...

432 quer dizer... eu acho que o português é muito usado/

433 quer dizer... existe um: um: teor de dominação sobre a língua...

434 a lingua ela participa para que haja uma classe dominante...

c) Comentários refutatórios - expressam opinião contrária ao que foi comentado anteriormente. Algumas vezes são introduzidos por gatilhos para abertura de espaços mentais, como mas e agora. No excerto (6), após o falante $\mathrm{W}$ ter apontado a quantidade de palavras num dicionário como critério para uma língua ser rica, a falante C refuta, nas unidades 345-346 e 349 a 351, tal visão. Na sequência, $\mathrm{W}$ explica-se melhor, refutando sua posição anterior.

\footnotetext{
${ }^{7}$ Os cerca de 30 minutos da conversa, analisada em Bernardo (1995, 2002), foram segmentados, conforme o tópico discursivo abordado, em três macroepisódios, subdivididos em episódios e eventos (Gorski, 1993, 1994). Tópico corresponde a um (...) "elemento sobre o qual se fala, (...) um ponto de referência do enunciado (1993, p. 32). Episódio é definido como uma "unidade semântico-discursiva que consiste em um conjunto de eventos relacionados e governados por um tópico central”; e evento como uma "unidade semântico-discursiva, constitutiva do episódio" (1994, p. 69-70).
}

Revista do GELNE, Natal/RN, Vol. 23 - Número 1: p. 201-216. Abril. 2021 
Excerto (6)

$\mathrm{C}=345$ eu- eu não tô questionando a:...a:...os verbetes... a quantidade de palavras...

346 tô dizendo a questão da riqueza... entendeu//

I= 347 riqueza da quantidade... né//

$[\mathrm{W}=($ inint.) $]$

$\mathrm{W}=348$ (ih comigo nesse caso não é não $\backslash$ )

$\mathrm{C}=349$ eu tô dizendo riqueza nu nu- na questão do valor da língua...

350 não existe... a- como não existe cultura superior a nenbuma outra...

351 a lingua também não é superior a nenbuma outra... entendeu/ /

$[\mathrm{W}=352$ num é....]

$\mathrm{W}=353$ mas não é a questã- que eu falei também naquela hora de riqueza foi um termo

(assim) errado que en coloquei... (inint.)

354 não foi em desvalorização sobre as outras...

355 mas sim da maneira que é flexivel em relação a:: a: ao sen- ao que você quer expressar... entende//

Os comentários de C relacionam-se aos espaços ATO DE FALA, EPISTÊMICO e METATEXTUAL, porque recrutam conhecimentos linguísticos teóricos para defender sua posição sobre o valor de uma língua, compartilhando suas posições com os falantes I e W. O comentário de W, por sua vez, além desses mesmos tipos de espaços ativados na BASE COMUM por C, também está conectado ao espaço metalinguístico, na medida em que $\mathrm{W}$ reavalia a expressão usada anteriormente, que levou à refutação de C.

d) Comentários demonstrativos - enunciados de natureza exemplificativa que não são expressos em forma de pequena narrativa. Funcionam como prova em relação ao que está sendo discutido e podem ser hipotéticos. No excerto (7), ilustra-se um caso desse tipo de comentário, cuja conceptualização recruta espaços ATO DE FALA, EPISTÊMICO, METATEXTUAL, visto que envolve conhecimentos ativados e compartilhados entre os falantes W e I, para defenderem suas posições acerca do caráter ideológico da língua, por meio do exemplo de Brizola.

Excerto $(7)$

$\mathrm{W}=574$ você quer um exemplo igual a esse... Leonel Brizola

$\mathrm{I}=575$ é...

$\mathrm{W}=576$ é um grande exemplo em relação... a linguagem...

$\mathrm{I}=577$ é verdade... é verdade...

578 tan- tanto é que ele é impedido de ir pra televisão...

$\mathrm{W}=579$ e se ele for pra televisão ele domina mesmo cara...

580 porque ele tem uma maneira de falar...

581 um jeito de falar que cativa as pessoas... /.../

e) Comentários de assentimento - complementam comentários anteriores, em concordância com o que foi expresso. Incluem-se, nessa categoria, os feedbacks. No excerto (8), exemplifica-se um caso desse tipo de comentário, em que se recrutam os espaços ATO DE FALA e METATEXTUAL, pois o falante $\mathrm{W}$ confirma com outras palavras a avaliação de I sobre a censura imposta pelos meios de comunicação.

Excerto (8)

I= 547 aí a Rede Globo... a Manchete... a Bandeirante chega lá...

548 "fala aí o que que tu acha da greve" //

549 aí o cara começou a falar eles tiram o microfone...

550 tum... acabou... vem o comercial... ((risos de W)) pra quê//

$\mathrm{W}=551$ é justamente isso...

552 o cara não pode nem cum- querer continuar a entrevista...

553 porque a Rede Globo vai selecionar... a comunicação... 
f) Comentários metadiscursivos - expressam uma avaliação sobre o próprio discurso dos participantes da interação ou sobre a linguagem utilizada por algum personagem em foco na conversa. No excerto (9), o falante I demonstra sua dificuldade de expressão. Pode-se considerar um caso de acesso ao espaço METALINGUístiCO em termos RECB.

Excerto (9)

$\mathrm{I}=445$ aquele negócio é:....

$$
\begin{aligned}
& {[\mathrm{W}=\text { não... depende muito da palavra (que você bota)...] }} \\
& \text { não tô conseguindo me expressar... }
\end{aligned}
$$

g) Comentários humorísticos - trechos de descontração e brincadeiras dos interlocutores que não são expressos em forma de pequena narrativa, como no caso do excerto (1). Como se pode observar no excerto (10), o caráter humorístico é codificado predominantemente no pretérito imperfeito do indicativo, para expressar um hábito recorrente entre os membros comilões da família; logo, não exprime um acontecimento delimitado e acabado num tempo passado, de modo a marcar um deslocamento de tempo em termos do aqui e agora da conversa. Tal como ocorre no caso dos comentários demonstrativos, a conceptualização recruta a ativação dos espaços ATO DE FALA, EPISTÊMICO, METATEXTUAL.

Excerto (10)

$\mathrm{I}=40$ você chegava lá pra fazer uma visita...

41 aquelesOLHOS... né// ((risos)) os olhos do lobo mau...

42 eles olhavam as partes mais carNUdas...

De modo geral, exemplos, pequenas narrativas e ilustrações humorísticas, frequentes em conversas, prestam-se a comprovações para as posições defendidas pelos participantes de uma interação, visto que conversas são naturalmente argumentativas, daí a postulação da ativação do espaço mental ATO DE FALA para conceptualização da maioria dos trechos analisados como comentários em Bernardo (1995). Essa concepção amplia a tipologia tradicional de atos de fala no âmbito da pragmática. Acredita-se que o fato de considerar a conversa como uma construção conjunta em termos processuais pelos participantes da interação licencia essa visão ampliada de ato de fala.

O fato de os comentários poderem ser incorporados à conceptualização reforça a adequação da RECB para descrição da organização conceptual (construal) de interações verbais. A fim de consolidar essa adequação teórica, passaremos à última etapa desta seção, apresentando a análise do excerto (11). No contexto anterior a esse excerto, os falantes W, I e C estavam especulando sobre a espessura do novo dicionário Aurélio ser maior que a do dicionário de inglês, o que levou o falante I a considerar a língua portuguesa mais rica em termos de quantidade de verbetes do que o inglês. Na sequência, na unidade de ideia 302, W caracteriza a língua portuguesa como mais rica do mundo, numa entonação ligeiramente exclamativa, introduzindo, assim, outro enfoque para a riqueza da língua portuguesa. A Figura 7 ilustra a RECB postulada para as unidades de ideia (doravante UI) 302 a 310.

Excerto (11)

$\mathrm{W}=302$ é a língua mais rica do mundo/

$\mathrm{I}=303$ (inint.) não de... considerar rica né/

$\mathrm{W}=304$ [é a língua mais rica/]

I= 305 não acho que seja riqueza não...

[W= 306 eu considero...]

$\mathrm{C}=307 \mathrm{eu}$ acho que-

$\mathrm{W}=308$ não é:... em termo de palavra... assim de expressão-

I= 309 não é riqueza não... Wilton... (não é riqueza não) 
$\mathrm{I}=311$ no Brasil...

[W= 310 não é riqueza não...

[[

$\mathrm{W}=312$ é uma coisa assim sabe-

$\mathrm{I}=\quad$ no Brasil... você tem um dicionário que tem cin:quenta mil verbete...

313 aí... há cem... um milhão de verbete...

314 não... essa é uma língua muito rica... por quê?

$\mathrm{W}=315$ eu considero rica porque...

[I= 316 acho um pouco prático $]$

ela- ela ela é:: fica mais fácil de explicar determinados termos...

317 que outras línguas não conseguem... entendeu//

$[\mathrm{C}=318$ esse termo... é errado usar se é mais rica ou menos rica...

319 não existe isso...

$\mathrm{I}=320$ é eu acho também

$\mathrm{C}=321$ língua é língua... seja ela-

Figura 7 - RECB das unidades de ideia 302 a 310

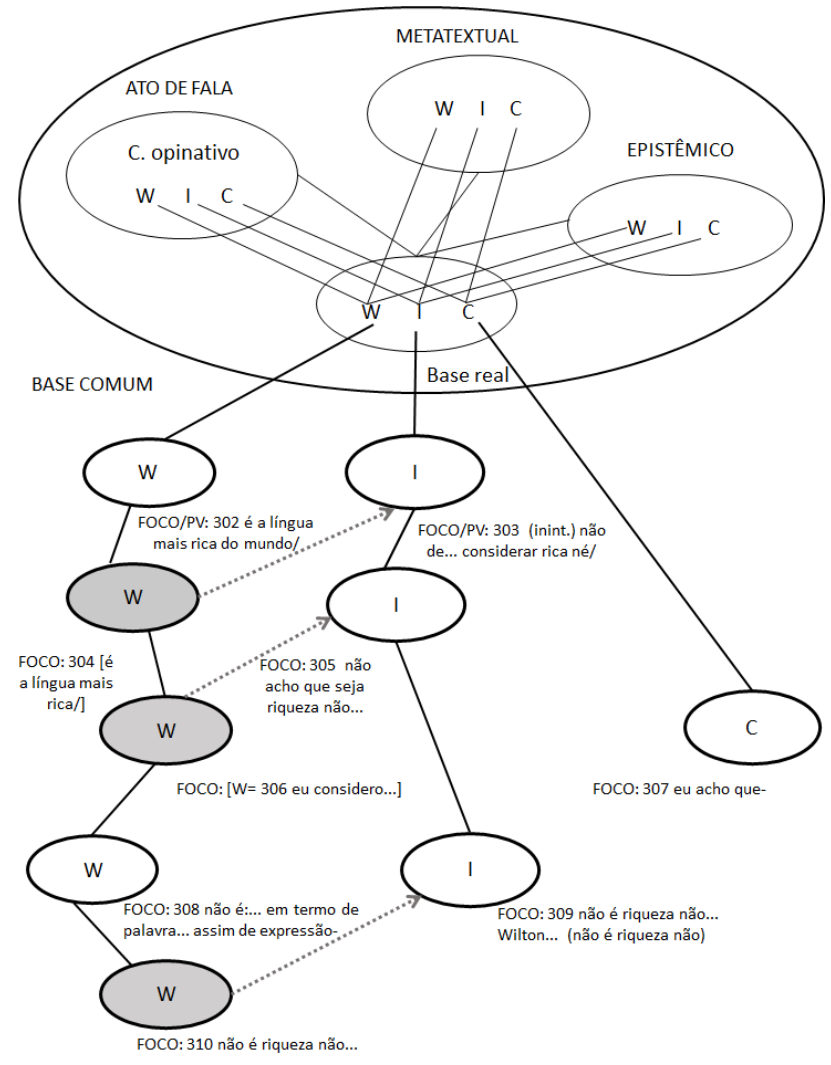

Fonte: Autores

Das UIs 302 a 310, os participantes da interação emitem opiniões sobre a riqueza da língua portuguesa: W e I adotam posições diferentes, por isso as UIs 302 e 303, além de representarem o conteúdo colocado em FOCO, também expressam um PONTO DE VISTA a partir do qual iniciam uma disputa de posições. Essa disputa se deve ao fato de, no contexto anterior ao excerto (11), o falante I ter se referido à riqueza em termos de quantidade de verbetes do dicionário Aurélio em relação a um dicionário de inglês do qual estava falando.

Ainda na representação da conceptualização do conteúdo, adotou-se uma configuração que espelhassem as alternâncias de turno. Nos casos de sobreposição de vozes, ou seja, um turno 
enunciado durante a fala de outro participante, o círculo foi preenchido com a cor cinza para sinalizar o espaço mental que representa a fala sobreposta. Além disso, uma seta pontilhada da mesma cor liga os espaços com trechos de sobreposição, apontando para o espaço referente ao turno que sofreu o "ataque". A conceptualização do conteúdo encontra-se ligada à BASE COMUM (GROUND), partilhada pelos interlocutores. Nessa BASE COMUM, ativam-se os espaços Base real, ATO DE FALA, METATEXTUAL, EPISTÊMICO.

O espaço Base real representa a Realidade situacional da interação: local, tempo, participantes. Por meio da Base real, ligada aos espaços de conteúdo, abre-se o espaço ATO DE FALA, em que se processam intenções comunicativas expressas por comentários opinativos trocados entre os falantes, cujas contrapartes são indicadas pelas iniciais de seus nomes. As opiniões estão ligadas a crenças conceptualizadas no espaço EPISTÊMICO. Crenças e intenções compartilhadas durante a interação são representadas também pelo espaço METATEXTUAL, na medida em que os conteúdos verbalizados são organizados e partilhados por meio de representação mental de discurso.

Devido à insistência de I de que não se trata de riqueza da língua portuguesa, o falante $\mathrm{W}$ na UI 310, começa a tentar se explicar melhor. Nesse fragmento, observa-se a tentativa da falante C emitir sua opinião na UI 307, cujo turno foi cortado por W (UI 308) e I na sequência (UI 309). A continuidade do excerto (11) é representada pela configuração da RECB na Figura 8.

Figura 8-RECB das unidades de ideia 311 a 321

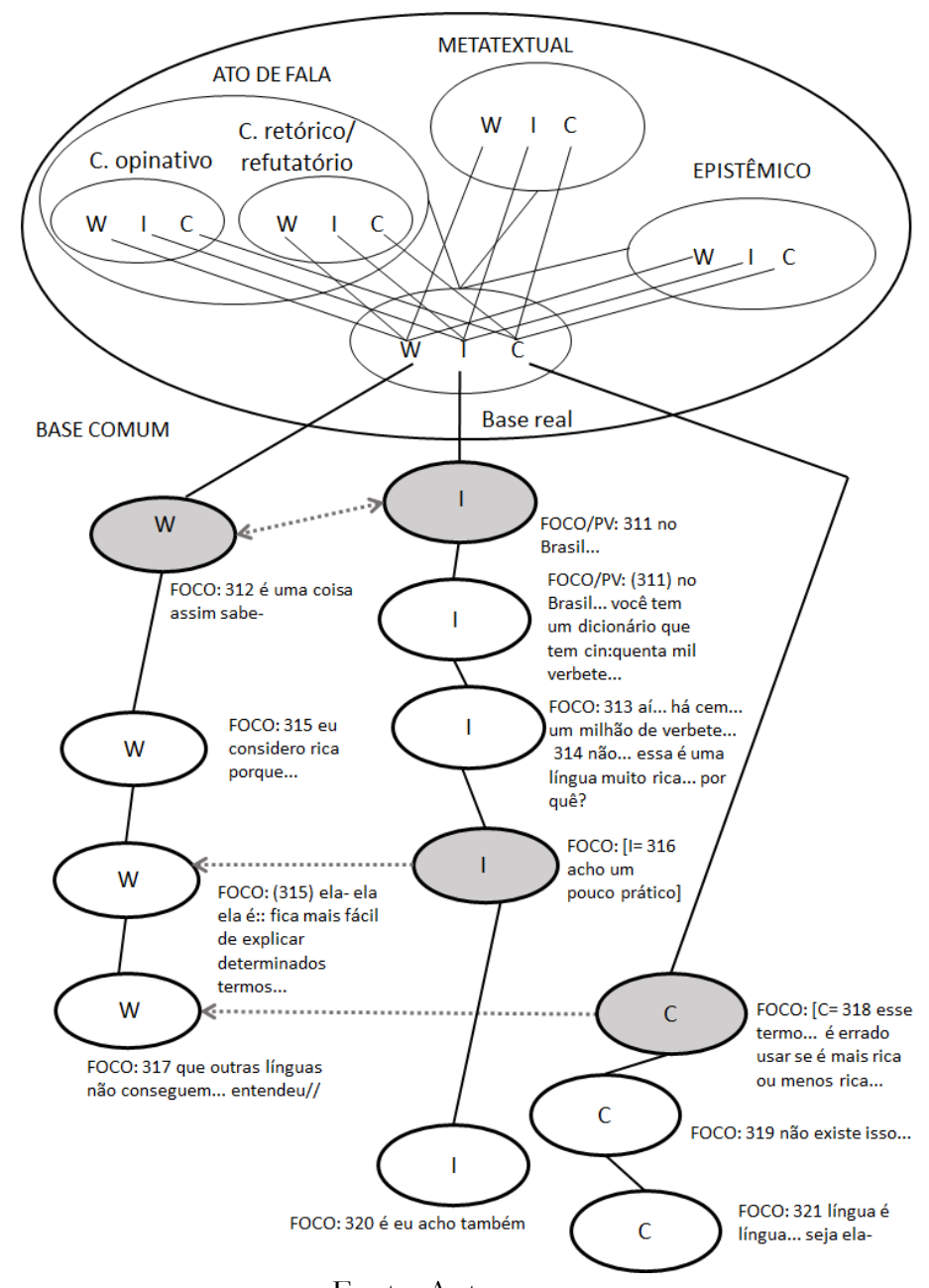

Fonte: Autores 
Os espaços de conteúdo conectam-se à BASE COMUM por intermédio da Base real, que mantém a representação situacional da Realidade da conversa. Nesse fragmento, o espaço ATO DE FALA representa o recrutamento não apenas opiniões, mas de enunciados de natura retórica: os comentários retóricos de I (UI 311, 313, 314) e W (UI 315, 316), bem como o comentário refutatório de C em 318-319, que resolve se impor, iniciando sua fala (UI 318) com sobreposição ao final da fala de W (UI 316), em discordância da posição de I e W, quanto ao conceito de riqueza. Esses diferentes tipos de ATOS DE FALA são representados em subespaços. Nas UIs 319 e 320, os falantes I e C alinham-se num posicionamento contrário ao de W. Na UI 321, C tenta continuar explicando a inadequação da avaliação de uma língua em termos de riqueza, mas é interrompida por $\mathrm{W}$, que retornará à questão da riqueza.

A mudança de estratégia discursiva, em razão dos comentários mais enfáticos de natureza retórica, em defesa dos pontos de vistas, motivou a abertura de uma nova RECB, visto que o teor do discurso foi alterado. Esse foi um critério adotado para mudança de configuração de rede nas experimentações representacionais ao longo da pesquisa. Os espaços EPISTÊMICO e METATEXTUAL desempenham a mesma função em relação ao fragmento anterior: processar as crenças evidenciadas pelos participantes e mantê-las organizadas num esquema mental de representação discursiva compartilhado ao longo do trecho, respectivamente.

\section{CONSIDERAÇÕES FINAIS}

As reflexões expostas neste artigo tiveram como principal objetivo demonstrar os caminhos percorridos para chegar a uma proposta de descrição da organização conceptual de interação verbal produzida e negociada pelos participantes com processamento online. Embora a análise tenha sido realizada a partir da transcrição, em que o caráter multimodal de conversas se perde, acredita-se que o modelo apresentado possibilitou refinamentos teóricos relevantes em relação ao estudo de Bernardo (2002). Em termos teóricos, espera-se ter destacado a adequação da noção de espaços conceptuais ativados e partilhados para descrição de aspectos linguísticos, contextuais e interacionais de conversas informais.

\section{REFERÊNCIAS}

BERNARDO, Sandra Pereira. Rede de Espaços Comunicativos Básicos na conceptualização de interações verbais. Rio de Janeiro: UERJ, Instituto de Letras, 2016. 42f. Projeto de Pesquisa.

BERNARDO, Sandra Pereira. Foco e ponto de vista na conversa informal: uma abordagem sócio-cognitiva. Rio de Janeiro: UFRJ, Faculdade de Letras, 2002. 221 f. Tese de Doutorado em Linguística.

BERNARDO, Sandra Pereira. Planos discursivos na conversa informal. Rio de Janeiro: UFRJ/Faculdade de Letras, 1995. Dissertação de Mestrado em Linguística.

CHAFE, Wallace. Cognitive constraints on information flow. In: TOMLIN, R. Coherence and grounding in discourse. Amsterdam/Philadelphia: John Benjamins, 1987.

CHAFE, Wallace. Linking intonation units in spoken English. In: HAIMAN, J. \& THOMPSON, S. (eds.). Clause combining in grammar and discourse. Amsterdam/Philadelphia: John Benjamins, 1988. p. $1-27$.

CLARK, Herbert H. Using language. Cambridge: Cambridge University Press, 1996.

DANCYGIER, Barbara; SWEETSER, Eve. Mental Spaces in Grammar: Conditional Constructions. Cambridge: Cambridge University Press, 2005.

FAUCONNIER, Gilles. Mappings in thought and language. Cambridge: Cambridge University Press, 1997.

FERRARI, Lilian; PINHEIRO, Diogo. Isso é muito bom para ser verdade: mesclagem e subjetividade em construções escalares. Scripta, Belo Horizonte, v. 18, n. 34, p. 85-102, $2^{\circ}$ sem. 2014. 
FERRARI, Lilian; SWEETSER, Eve. Subjectivity and upwards projection in mental space structure. In: DANCYGIER, Barbara; SWEETSER, Eve (eds.). Viewpoint in language: a multimodal perspective. Cambridge: Cambridge University Press, 2012. p.47-68.

GORSKI, Edair Maria. Iconicidade e topicidade no discurso narrativo. In: VOTRE, S. (org.) Iconicidade - Funcionalismo em Linguística. Rio de Janeiro: UFRJ/Faculdade de Letras, 1993. p. 1640.

GORSKY, Edair. O tópico semântico-discursivo na narrativa oral e escrita. Rio de Janeiro: UFRJ/Faculdade de Letras, 1994. Tese de doutorado.

RONCARATI, Cláudia (org.). Banco de dados interacionais. Rio de Janeiro: Faculdade de Letras UFRJ/CNPq, 1996.

SACKS, H.; SCHEGLOFF, E. E.; JEFFERSON, G. A simplest systematics for the organization of turn-takiing for conversation. Language. /s.l./, 1974. 50. v., p. 696-735.

SANDERS, T.; SANDERS, J.; SWEETSER, E. Causality, cognition and communication: a mental space analysis of subjectivity in causal connectives. In: SANDERS, T.; SWEETSER, E. (Orgs.). Causal categories in discourse and cognition. Berlin/New York: Mouton de Gruyter, 2009.

Submetido em $02 / 11 / 2020$

Aceito em 03/03/2021 